\title{
Não intervenção do CNJ no regime de precatórios
}

Conselho Nacional de Justiça (CNJ)

PEDIDO DE PROVIDÊNCIAS № 0003350-69.2013.2.00.0000

RELATOR: CONSELHEIRO JEFFERSON KRAVCHYCHYN

REQUERENTE:SERVIÇOSDETERRAPLANAGEMEEMPREENDIMENTOS LTDA - SETEL E OUTROS

REQUERIDO: TRIBUNAL DE JUSTIÇA DO ESTADO DA BAHIA

EMENTA: RECURSO ADMINISTRATIVO. PEDIDO DE PROVIDÊNCIAS. TRIBUNAL DE JUSTIÇA DO ESTADO DA BAHIA. REGIME DE PRECATÓRIOS. NÃO COMPETÊNCIA DO CNJ. PRECEDENTES. RECURSO CONHECIDO. NEGADO PROVIMENTO.

1) Consoante a jurisprudência atual do Conselho Nacional de Justiça, não cabe a este imiscuir-se nos procedimentos alusivos à expedição e cumprimento de precatórios judiciais, ainda que ostentem nítido viés administrativo, pois funcionar como instância ordinária revisora das decisões nestes proferidas inviabilizaria o exercício de suas demais competências cometidas constitucionalmente. Procedimento de controle administrativo não conhecido; Precedentes do CNJ.

2) Recurso conhecido e negado provimento. 


\section{Vistos.}

Trata-se de Recurso Administrativo em Procedimento de Controle Administrativo (PCA) instaurado por Serviços de Terraplanagem e Empreendimentos LTDA - SETEL e outros, em face da decisão monocrática DEC19 que determinou o arquivamento do presente processo por entender que a matéria não é competência do Conselho Nacional de Justiça.

Em apertada síntese, as requerentes alegaram, no pedido inicial, que o Tribunal está sendo complacente e permissivo com as atitudes do Governo baiano, o que tem gerado a inadimplência parcial, porém significativa, deste em relação à parcela $\mathrm{n}^{\mathrm{o}}$ 1/14, que deveria ter sido integralmente quitada em 2011, e a injustificada recusa do TJBA a empreender a correta destinação, em benefício das requerentes, do saldo residual do depósito da parcela no 1/13, correspondente ao exercício de 2012 (REQINIC1).

Em caráter de urgência, o Tribunal prestou as informações que entendeu de direito (INF13).

Na DEC15, indeferi o pedido liminar, sob o argumento de que

dada a impossibilidade de reversão da tutela acautelatória, que é, na esteira da melhor doutrina processualista, um dos seus requisitos. A concessão liminar do pedido, no presente caso, é o mesmo que o provimento definitivo do pedido, que, inclusive, em face da matéria discutida, não pode ser deferida monocraticamente, dada a complexidade que o caso apresenta.

Em face dessa decisão, as requerentes, pedindo a reconsideração, alegaram que o pedido liminar era no sentido de determinar que o TJBA não tomasse qualquer medida na gestão dos recursos pendentes na conta especial destinada à gestão dos precatórios devidos pelo Estado da Bahia - resíduos da parcela 1/13 (exercício de 2012), em valor de aproximadamente R $\$ 48$ milhões (PET16).

No DESP17, determinei que fossem aguardadas as informações do Tribunal de Justiça do Estado da Bahia.

Insurgindo novamente, as requerentes insistiram na reconsideração da DEC15 para a concessão da liminar requerida.

No DEC19, determinei o arquivamento do presente processo por entender que a matéria não é competência do Conselho Nacional de Justiça. 
Em suas razões recursais, as requerentes alegam que é contraditória a afirmação de que o Conselho Nacional de Justiça não tem competência para analisar e controlar a atuação dos tribunais no que tange ao regime dos precatórios. Ademais, pontuam que

não bastasse isto, soaria no mínimo estranho admitir que o $\mathrm{C}$. CNJ possuísse o poder de regulamentar a forma de atuação dos Tribunais de Justiça na gestão de precatórios, mas não tivesse suficiente poder para controlar os respectivos atos. Admitir-se isso, por uma questão de apuro terminológico, ter-se-ia de passar a chamar as diversas "resoluções" deste Órgão de meras "recomendações".

No mérito, aduzem que o Tribunal não refutou qualquer fato alegado, ao contrário, confirmou (PET20).

É sucinto o relatório.

\section{Voto:}

Preliminarmente, conheço do recurso pelo atendimento do requisito temporal (art. 115 do RICNJ) e do interesse recursal.

No mérito, voto pela manutenção integral dos termos da decisão monocrática DEC19:

Tendo em vista a matéria que encerra os autos, analisando mais detidamente a matéria posta, verifico que a questão pode ser enfrentada sem as manifestações do Tribunal de Justiça do Estado da Bahia.

Por expressa disposição constitucional (art. 100), cabe ao Poder Judiciário a gestão dos pagamentos das dívidas do Poder Público, pelo regime dos precatórios. Contudo, é pacífica a jurisprudência deste Conselho no sentido que não cabe ao $\mathrm{CNJ}$

imiscuir-se nos procedimentos alusivos à expedição e cumprimento de precatórios judiciais, ainda que ostentem nítido viés administrativo, pois funcionar como instância ordinária revisora das decisões nestes proferidas inviabilizaria o exercício de suas demais competências cometidas constitucionalmente. (CNJ - PCA - Procedimento de Controle Administrativo - 0002416-19.2010.2.00.0000 - Rel. IVES GANDRA - 104ª Sessão - j. 4/5/2010) 
Abaixo, colaciono a farta jurisprudência deste Conselho sobre o assunto: RECURSO ADMINISTRATIVO EM PEDIDODE PROVIDÊENCIAS. GLOSA DE VERBA EM PROCESSO DE PAGAMENTO DE PRECATÓRIOS. VIOLAÇÃO À RESOLUÇÃO № 115 DO CNJ. NÃO CONHECIMENTO.

1. Trata-se de Recurso Administrativo em Pedido de Providências interposto pelo Sindicato dos Auditores Fiscais da Fazendo do Estado do Piauí contra decisão monocrática que determinou o arquivamento liminar de pedido contra ato do Presidente do Tribunal de Justiça que determinou a exclusão de condenação honorária constante de processo de execução, em sede de atualização de valores para pagamento de precatórios em nome do requerente.

2. Não há, no pedido do requerente, motivo que determine a intervenção deste Conselho. Eventual injustiça na decisão de processamento do precatório deve ser diretamente acionada no Tribunal de origem, isso porque, embora tenha natureza administrativa, o processamento de precatórios não torna o CNJ instância ordinária de revisão das decisões preferidas nesses procedimentos quando possível a utilização da via judicial. Precedentes.

3. O fundamento para não intervir deriva da própria distribuição de competências da Constituição Federal. Com efeito, é impossível de se cogitar a possibilidade deste Conselho Nacional de Justiça impor ordem de pagamento ou, até mesmo, de sequestro de valores a um outro poder.

4. Ainda que se insistisse em adentrar no mérito do presente caso, impõe-se $o$ desprovimento do recurso. Com efeito, a fixação de honorários pelo desprovimento de embargos à execução não ocorreu, ao menos não explicitamente. Contra eventual omissão da sentença, caberiam embargos de declaração, em prazo preclusivo de cinco dias. Não há notícias de que os embargos tenham sido opostos. Apenas mais tarde é que foi protocolado requerimento para se fixar expressamente a condenação em honorários. Apenas com a extemporânea provocação do requerente é que o Juiz de Direito da $2^{a}$ Vara dos Feitos da Fazenda Pública, em despacho proferido após a emissão da ordem de pagamento, autoriza a inclusão de honorários. Não obstante a controvérsia e o caráter judicial desse provimento, há dúvidas suficientes de modo a justificar que o Presidente do Tribunal o despreze, tal qual o faria se nulo ou inexistente.

5. Recurso conhecido e desprovido.

(CNJ-RA - Recurso Administrativo em PP - Pedido de Providências - 
Conselheiro - 0005613-45.2011.2.00.0000 - Rel. NEVES AMORIM 158 a Sessão $-j$. 13/11/2012).

RECURSO EM PROCEDIMENTO DE CONTROLE ADMINISTRATIVO. PRECATÓRIOS. PEDIDO PARA INCLUSÃO DE MUNICÍPIO NO REGIME ANUAL DE PAGAMENTO. NÃO CONHECIMENTO.

1. Trata-se de Recurso Administrativo em sede de Procedimento de Controle Administrativo interposto contra decisão do Tribunal de Justiça do Estado de São Paulo que determinou a um município o pagamento de precatórios na forma do disposto no art. 97 do ADCT.

2. Há orientação sedimentada por este Conselho no sentido de não ter competência para controlar atos afetos ao processamento de precatórios, ainda que de natureza administrativa o respectivo iter procedimental.

3. Embora tempestivo, deve-se desprover o presente Recurso.

(CNJ-RA - Recurso Administrativo em PCA - Procedimento de Controle Administrativo - 0005663-37.2012.2.00.0000 - Rel. NEVES AMORIM 158ํㅗㄹ Sessão - j. 13/11/2012).

RECURSO EM PROCEDIMENTO DE CONTROLE ADMINISTRATIVO. TRIBUNAL REGIONAL DO TRABALHO DA 16a REGIÃO. DETERMINAÇÃO DE RETENÇÃO DE REPASSE DO FUNDO PARTICIPAÇÃO DE MUNICÍPIOS PARA PAGAMENTO DE PRECATÓRIOS JUDICIAIS. NÃO CONHECIMENTO.

1. Pretensão de desconstituição decisão proferida Juízo Auxiliar de Precatórios do Tribunal Regional do Trabalho da 16a Região no Processo Administrativo $n^{\underline{a}}$ 279/2005, que determinou ao Banco do Brasil a retenção de valores correspondentes a 5\% (cinco por cento) dos repasses do Fundo de Participação dos Municípios - FPM, para o pagamento de precatórios judiciais.

2. Este Conselho já fixou a sua interpretação no sentido de que a natureza administrativa da atividade desenvolvida no processamento de precatórios não torna o CNJ instância ordinária de revisão das decisões proferidas nesses procedimentos.

3. Não há fatos ou argumentos novos que justifiquem a rediscussão da matéria pelo Plenário deste Conselho. 
Recurso a que se nega provimento. (CNJ - RA - Recurso Administrativo em PCA - Procedimento de Controle Administrativo - 0000162 39.2011.2.00.0000 - Rel. JOSÉ ADONIS CALLOU DE ARAÚJO SÁ 121a Sessão - j. 01/03/2011).

PROCEDIMENTO DE CONTROLE ADMINISTRATIVO - PRECATÓRIO - REVISÃO DE CÁLCULOS - INCOMPETÊNCIA DO CNJ - NÃO CONHECIMENTO. Consoante a jurisprudência atual do Conselho Nacional de Justiça, não cabe a este imiscuir-se nos procedimentos alusivos à expedição e cumprimento de precatórios judiciais, ainda que ostentem nítido viés administrativo, pois funcionar como instância ordinária revisora das decisões nestes proferidas inviabilizaria o exercício de suas demais competências cometidas constitucionalmente. Procedimento de controle administrativo não conhecido.

(CNJ - PCA - Procedimento de Controle Administrativo - 000241619.2010.2.00.0000 - Rel. IVES GANDRA - 104ª Sessão - j. 04/05/2010).

RECURSO ADMINISTRATIVO EM PROCEDIMENTO DE CONTROLE ADMINISTRATIVO. PRECATÓRIO. INCOMPETÊNCIA DO CNJ. A jurisprudência recente do CNJ entende ser incompetente o Conselho para revisar decisões acerca da expedição ou cumprimento de precatórios, apesar do caráter administrativo da matéria. (CNJ-RA - Recurso Administrativo em PCA - Procedimento de Controle Administrativo - 000082408.2008.2.00.0000 - Rel. PAULO LÔBO - 65ํㅗ Sessão - j. 24/06/2008).

PEDIDO DE PROVIDÊNCIAS - PRECATÓRIO - SEQUESTRO DE VALOR - ALEGAÇÃO DE DESCUMPRIMENTO DA ORDEM CRONOLÓGICA - NATUREZA ADMINISTRATIVA DA DECISÃO INDEFERIMENTO

I. A natureza administrativa da atividade desenvolvida no processamento de precatórios não torna este Conselho instância ordinária revisional de decisões proferidas nesses procedimentos. Precedente (PCA 8462).

II. Pedido de providências não conhecido (CNJ - PP - Pedido de Providências - Conselheiro - 0001649-83.2007.2.00.0000 - Rel. Mairan Gonçalves Maia Júnior - 57a Sessão - j. 26/02/2008). 
CONSULTA. PRECATÓRIOS. NÃO REPASSE DE VERBA POR PARTE DO ENTE PÚBLICO DEVEDOR. SEQUESTRO. HIPÓTESES CONSTITUCIONAIS. PONDERAÇÃO DE VALORES.

1- A Emenda Constitucional no 62/09 instituiu o regime especial de pagamento de precatórios.

2- O Superior Tribunal de Justiça firmou entendimento de que o disposto na Emenda Constitucional no 62/09 aplica-se imediatamente aos processos em curso, pois se trata de norma de natureza procedimental, não existindo direito adquirido à manutenção de regime jurídico.

3 - Com a revogação tácita do art. 78 do ADCT, a possibilidade de sequestro de rendas públicas, condicionada ao requerimento do credor, foi mantida, mas tão somente nos casos de preterição do direito de preferência e de não alocação de verba orçamentária do valor necessário à satisfação do débito.

4- Não é atribuição do Conselho Nacional de Justiça, por expressa disposição constitucional, atuar como órgão revisor de eventuais decisões judiciais adotadas no processamento de precatórios e, tampouco, o de substituir o próprio Judiciário na tarefa de aplicar o direito ao caso concreto.

5 - As circunstâncias do caso concreto é que indicarão se a medida administrativa do sequestro de verbas públicas, estritamente dentro das hipóteses constitucionalmente previstas, se mostra razoável e proporcional, em relação aos recursos disponíveis pelo Estado para atendimento dos serviços públicos essenciais.

(CNJ - CONS - Consulta - 0002296-05.2012.2.00.0000 - Rel. SÍLVIO ROCHA - 156⿳亠口冋 Sessão $-j$. 16/10/2012).

Veja-se que a atuação do $\mathrm{CNJ}$, no presente caso, poderia macular a relação entre os poderes da Federação, ao passo que se estaria imiscuindo em ato do Poder Executivo do ente federado. A propósito, colaciono interessante e lúcida argumentação do Conselheiro Neves Amorim, nos autos do Pedido de Providências - no 0005613-45.2011.2.00.0000:

O fundamento para não intervir deriva da própria distribuição de competências da Constituição Federal. Com efeito, é impossível de se cogitar a possibilidade deste Conselho Nacional de Justiça impor ordem de pagamento ou, até mesmo, de sequestro de valores a um outro poder. Consabido, o Supremo Tribunal já fixou reiteradas vezes 
o caráter de órgão de controle interno do Poder Judiciário que ostenta este Conselho, razão pela qual as decisões que emite apenas geram efeitos para os órgãos do Poder Judiciário. A contrario sensu, poderia haver casos em que o provimento de eventual recurso aqui emitido contenha elementos de uma representação interventiva.

Não se está a afirmar que o CNJ não poderia disciplinar o processo administrativo, geral e abstrato, que deve pautar a atuação dos Tribunais em sede de precatórios. Tampouco se poderia concluir que a atuação dos Presidentes dos Tribunais estaria imune de eventual responsabilização disciplinar. A Emenda Constitucional no 62 não autoriza nenhuma dessas conclusões, como se infere claramente do disposto no art. 100, §7ํ da Constituição Federal. Mas é evidente que a atuação é limitada: deve amoldar-se ao complexo feixe de competências dos demais órgãos e entes federativos.

Assim, é descabida a hipótese de o Conselho Nacional de Justiça determinar o sequestro de quaisquer quantias, no processamento da gestão de precatórios, como querem as requerentes.

Ante o exposto, voto pelo conhecimento do recurso, mas pelo seu improvimento.

Intimem-se.

Brasília, 19 de julho de 2013.

\section{Conselheiro JEFFERSON KRAVCHYCHYN}

Relator 